\title{
Eddy Seeding in the Labrador Sea: A Submerged Autonomous Launch Platform Application
}

\author{
Heather H. Furey, M. Femke de Jong, James R. Valdes, And Amy S. Bower \\ Department of Physical Oceanography, Woods Hole Oceanographic Institution, Woods Hole, Massachusetts
}

(Manuscript received 27 March 2013, in final form 26 July 2013)

\begin{abstract}
Two submerged autonomous launch platforms (SALPs) were deployed at 500-m depth on a deep-water mooring in the northeastern Labrador Sea from 2007 to 2009 to automatically release profiling floats into passing warm-core anticyclonic Irminger Rings (IRs). The objective was to investigate the rings' vertical structure and evolution as they drifted from their formation site near the western coast of Greenland to the area of deep convection in the south-central part of the basin. Mechanically and electronically, the SALP worked well: 10 out of 11 floats were successfully released from the mooring over 2 years. However, getting floats trapped in eddy cores using a preprogrammed release algorithm based on temperature and pressure (a proxy for current speed) measured by the SALPs met with limited success mainly because 1) the floats settled at a park pressure that was initially too deep, below the volume of water trapped in the eddy core; 2 ) the eddies translated past the mooring much more quickly than anticipated; and 3) there is a seasonal cycle in both background and eddy core temperature that was not known a priori and therefore not accounted for in the release algorithm. The other mooring instruments $(100-3000 \mathrm{~m})$ revealed that 12 anticyclones passed by the mooring in the 2-yr monitoring period. Using this independent information, the authors assessed and improved the release algorithm, still based on ocean conditions measured at one depth, and found that much better performance could have been achieved with an algorithm that allowed for faster eddy translation rates and the seasonal temperature cycle.
\end{abstract}

\section{Introduction}

Deep ocean convection is limited to a small number of isolated regions worldwide, including the Labrador Sea, but it has a profound impact on the ocean's thermohaline circulation and climate. The decay of coherent, long-lived, anticyclonic eddies shed from a surrounding warm boundary current is important in restratifying convection regions (Spall 2004; Katsman et al. 2004; Gelderloos et al. 2011). In the Labrador Sea, anticyclonic eddies, or Irminger Rings (IRs), form in a localized region over the continental slope off the western coast of Greenland (Fig. 1), and generally drift slowly southward into the interior Labrador Sea (Lilly et al. 2003 , hereafter L03), carrying a core of warm salty water from the Irminger Current. Most of what is known about the hydrographic and velocity structure of what are possibly older rings (Lilly and Rhines 2002) is from moored

Corresponding author address: Heather Furey, Woods Hole Oceanographic Institution, 266 Woods Hole Road, MS 21, Woods Hole, MA 02543.

E-mail: hfurey@whoi.edu observations near the site of the former ocean weather ship Bravo (Bravo; Fig. 1), which is about $500 \mathrm{~km}$ away from the formation site. From glider observations of rings in the boundary formation region, we know that in addition to a warm, salty core at intermediate depths, some new rings have a cap of much colder, fresher water of Arctic origin (Hátún et al. 2007, hereafter H07). How the heat and freshwater anomalies trapped in these eddies are distributed within the Labrador Sea has potentially major implications for the annual and interannual variability in stratification and where deep convection occurs (Lazier 1980; Lazier et al. 2002; Pickart et al. 2002; L03; Straneo 2006a,b; Gelderloos et al. 2011).

Several investigators have attempted to quantify the impact of IRs on the heat and freshwater budgets of the Labrador Sea (e.g., L03; H07). These estimates suffer from a lack of information on the initial structure of IRs and on the site within the Labrador Sea where they deposit their anomalous core properties: the glider observations were in rings embedded in the boundary current, the Bravo site measurements were far removed from the formation site, and the intervening altimetric measurements often are not able to consistently detect 


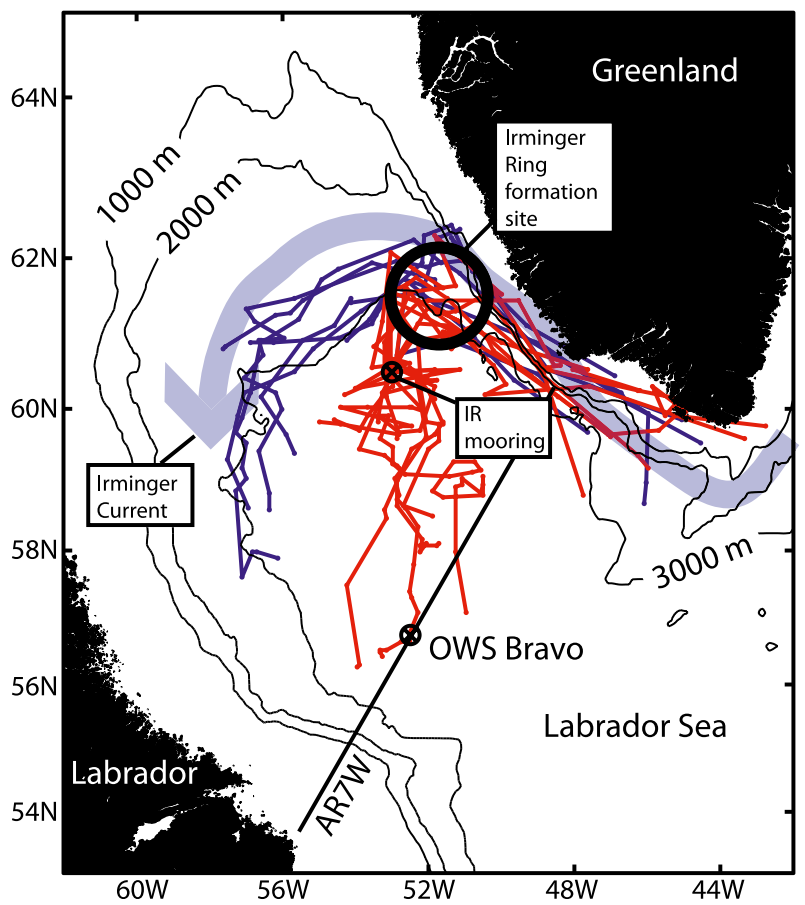

FIG. 1. IR mooring site location (circled $\mathrm{x}$ ) with subjectively tracked anticyclones from gridded AVISO sea level anomaly data for the years 2001 through 2006. Several anticyclones fell into two categories: those that remained in the Irminger Current and traveled cyclonically around the Labrador Sea (blue lines) and those that were shed into the interior Labrador Sea and drifted to the south (red lines), generally toward ocean weather ship Bravo. The repeat survey line AR7W is shown.

the small diameter (relative to altimetric ground track spacing) eddies at the surface (de Jong et al. 2013, manuscript submitted to J. Phys. Oceanogr., hereafter DJ). The goal of the Irminger Rings Experiment was to advance our understanding of the role of IRs in restratification by collecting new information on their initial structure and on the decay of their core properties as they propagate across the Labrador Sea. To meet this goal, we deployed one densely instrumented mooring in the northeastern Labrador Sea near, but offshore of, the eddy formation site to document the full water column hydrographic and velocity structure of new IRs where they detach from the boundary and enter the interior (Figs. 1 and 2).

The mooring also served as the "launch pad" for the automatic release of a profiling float each time an eddy swept by the mooring using a submerged autonomous launch platform (SALP; Fratantoni 2013). We proposed that the floats, trapped within the eddies by the strong azimuthal velocities, would track the eddy trajectories and measure changes in eddy core properties as they move from the formation region. The SALP, designed and field tested by Fratantoni (2013), was built to use

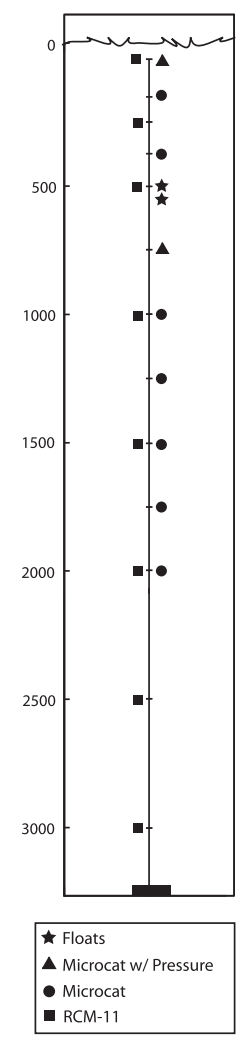

FIG. 2. Configuration of instruments on the IR mooring. The two SALP frames were located at $500-\mathrm{m}$ depth, indicated by the stars. The SALPs contain their own thermistors and pressure sensors and use these data alone to react to changing oceanographic conditions.

a full water column array of instruments that communicated to the SALP controller via acoustic modems. It was designed to release drifters (in the field tests, surface drifters) when a defined set of criteria were met. We simplified the prototype SALP and released floats based on ambient ocean criteria at a single depth, to seed IRs that intersected the mooring. IR observations by L03 and H07 allowed us to choose single-depth criteria unique to these warm-core deep-reaching anticyclones. By limiting the communication to just the thermistor and pressure sensors on the SALP cage, we hoped to utilize the SALP in a simpler, and therefore cost effective, manner while still correctly identifying IRs.

This paper reviews the performance of this application of the SALP. The other mooring instruments recorded 12 robust anticyclones, a combination of IRs and boundary current eddies (BCEs; e.g., Chanut et al. 2008) in the 2-yr monitoring period from September 2007 to September 2009 (DJ). With this independent and concurrent information, we assess the effectiveness of the SALP controller algorithm, which utilized temperature and pressure criteria to identify IRs. Under the constraint of optimizing the SALP algorithm using 
ocean properties only at the SALP depth, we develop algorithms that use different combinations of temperature, pressure, density, and velocity criteria as well as different averaging windows. In the following section, we outline the field experiment details. In section 3, we describe the anticyclone observations in the mooring record, detail the SALP releases, and discuss the first-time use of the Autonomous Profiling Explorer (APEX; Davis et al. 2001) float for automatically seeding eddies. In section 4, we discuss algorithm improvements that could be made to the original controller code used in the field. In section 5, we develop and compare algorithms based on other properties. We summarize our findings in section 6 .

\section{Experiment design}

\section{a. Mooring site location}

The mooring site was chosen to be in a location likely to be populated with IRs, based on a map of the percentage of Ocean Topography Experiment (TOPEX) cycles inside anticyclonic eddy cores from L03. This percentage diagram was derived from wavelet analysis of along-track Archiving, Validation, and Interpretation of Satellite Oceanographic data (AVISO) sea level anomaly (SLA) data from 1994 to 2000 . To confirm the stability of the site position for our 2007 deployment date, we also examined the gridded AVISO SLA data from 2001 to 2006 . We subjectively tracked anticyclone (circular patches of high SLA at least $15 \mathrm{~cm}$ greater than the surrounding SLA field) pathways using a movie of gridded SLA and the Matlab "ginput.m" function, which allowed us to tag and save eddy positions frame by frame and create trajectories (Fig. 1, blue and red trajectories). Some of the anticyclones tracked fell into two groups: eddies that stayed in the boundary current, and circumnavigated the Labrador Sea (blue trajectories), and those that left the boundary current in the northeast and traveled into the interior basin (red trajectories). (Note that it was not possible to match and track eddies observed at the 2007-09 mooring with SLA data; see DJ.) Both the objective identification of positive SLA anomalies (L03) and the subjective anomaly tracking resulted in a similar pathway for IR propagation across the interior Labrador Sea and over the proposed SALP mooring site.

\section{b. IR characteristics and float retention}

In 2007, when the mooring was deployed, the best observations of the anticyclones we were attempting to tag originated from the Bravo mooring, $500 \mathrm{~km}$ from our mooring site (Fig. 1). At that location, the IRs had "bowls" of warm high-salinity water from the Irminger

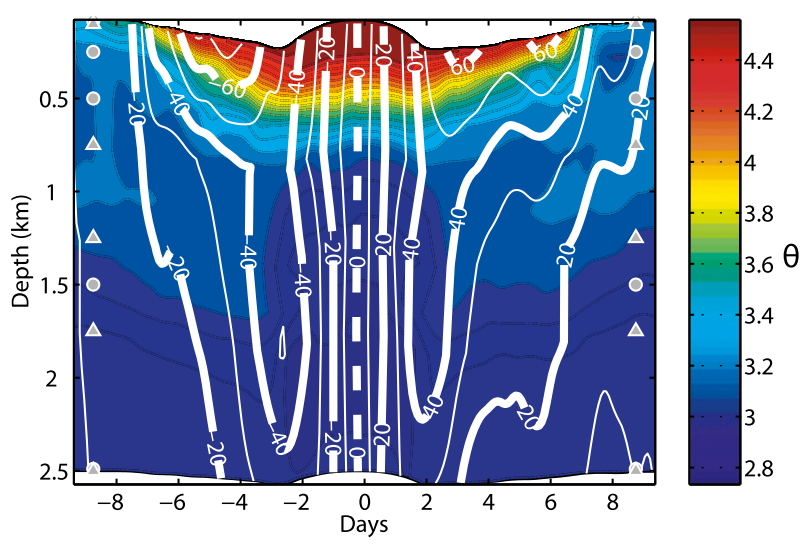

FIG. 3. Velocity $\left(\mathrm{cm} \mathrm{s}^{-1}\right)$ and temperature $\left({ }^{\circ} \mathrm{C}\right)$ structure of a warm, anticyclonic Irminger Ring observed at the Bravo mooring during 1998. The time axis is in days relative to the eddy center.

Current extending sometimes as deep as $1000 \mathrm{~m}$, surfaceintensified velocity structure with a maximum of up to $80 \mathrm{~cm} \mathrm{~s}^{-1}$ at a core radius of $23 \mathrm{~km}$, and significant eddy currents to at least $2500 \mathrm{~m}$ (L03; Fig. 3). The Bravo eddies passed over the mooring, from leading eddy wall maximum velocity to trailing eddy wall maximum velocity, in about 4 days. Two Seagliders (Eriksen et al. 2001) deployed for 5-month trial missions encountered three young Irminger Rings in 2005 (H07) embedded in the boundary current that was being advected at about $15 \mathrm{~cm} \mathrm{~s}^{-1}$. One eddy had a characteristic warm and saline core in the depth range 300-1000 m (maximum dive depth), about $1^{\circ}-1.5^{\circ} \mathrm{C}$ and 0.1 practical salinity units above background values and extending out to a radius of $35 \mathrm{~km}$. Vertically averaged azimuthal velocity was $50 \mathrm{~cm} \mathrm{~s}^{-1}$ at a core radius of $25 \mathrm{~km}$. Speeds exceeding $40 \mathrm{~cm} \mathrm{~s}^{-1}$ extended to at least $1000 \mathrm{~m}$.

Using the observations by $\mathrm{L} 03$ and $\mathrm{H} 07$, we programmed the SALP controller to release a float when an IR was detected at the mooring. The rings have a distinct warm core, so the temperature at the depth of the warm core (e.g., $500 \mathrm{~m}$ ) is a robust indicator of a ring. But since the water property anomalies extend radially beyond the velocity core (L03; H07), there was some risk of a float being released on the eddy flank, quickly separating from the eddy, or in a warm filament. The algorithm developed for this SALP application depended on both temperature and indirectly on velocity to ensure that floats were released within the trapped fluid of a warm eddy core. The method took advantage of the relationship between velocity, its friction on the mooring, and resultant mooring towdown. Figure 4 illustrates the approximate vertical displacement of a mooring as a Gaussian-shaped eddy with a maximum vertically averaged azimuthal velocity of $50 \mathrm{~cm} \mathrm{~s}^{-1}$ at a core radius of $21 \mathrm{~km}$ passes the mooring at four different radii. The 

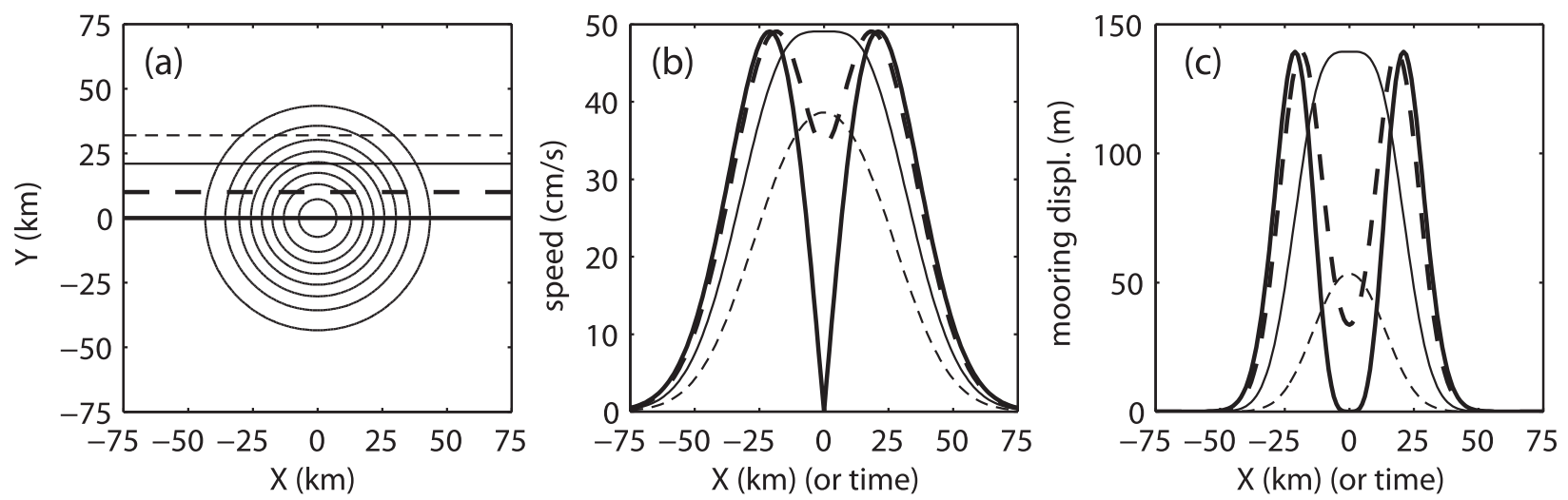

FIG. 4. Response of a mooring to the passage of an isolated eddy. (a) Stream function field for Gaussian eddy with maximum vertically averaged azimuthal speed of $50 \mathrm{~cm} \mathrm{~s}^{-1}$ at a core radius of $20 \mathrm{~km}$, with mooring slices at four different radii. (b) Absolute value of azimuthal velocity and (c) vertical displacements of the mooring for the four slices.

two slices through the eddy's velocity core (at $Y=0$ and $10 \mathrm{~km}$, heavy solid and dashed lines) result in two $\sim 150$-m towdowns of the mooring (Fig. 4c), whereas the two slices at the edge of and outside the core (thin solid and dashed lines, $Y=20$ and $30 \mathrm{~km}$ ) produce a single towdown. The algorithm targeted the "double-dip" shaped pressure record that occurs when an eddy passes directly over the mooring.

The APEX floats, or APEX, were ballasted to drift, or park, at $300 \mathrm{dbar}$ and profile from the surface to $1000 \mathrm{~m}$ once every 5 days to collect temperature and conductivity profile data (Davis et al. 2001). The APEX park pressure was chosen because it is in the main velocity core of the eddy but below the influence of wind. At the surface, the float telemetered its profile and drift data via Iridium satellite to a ground station, where it was retrieved via e-mail. Once a float was released in an eddy core at the park depth, two factors were thought to contribute to float trapping within the eddy for a significant fraction of its lifetime. First, Iridium float data transmission time at the sea surface is $\sim 15 \mathrm{~min}$. Over this time, an ageostrophic radial speed of $50 \mathrm{~cm} \mathrm{~s}^{-1}$ would result in a radial displacement of only $0.5 \mathrm{~km}$, which is only $\sim 1 \%$ of the eddy core diameter measured at Bravo. Second, azimuthal eddy speeds recorded in previous IRs were strong and deep reaching. Maximum azimuthal velocity averaged over the top $1000 \mathrm{~m}$ was measured at $\sim 50 \mathrm{~cm} \mathrm{~s}^{-1}$ (L03; H07) or 10 times larger than the $5 \mathrm{~cm} \mathrm{~s}^{-1}$ translation speed determined for many eddies in the interior (L03). At $5 \mathrm{~cm} \mathrm{~s}^{-1}$, the eddy core is well within the patch of trapped fluid traveling with the eddy (Flierl 1981; Regier and Stommel 1979). Even at $15 \mathrm{~cm} \mathrm{~s}^{-1}$, the translation rate observed by $\mathrm{H} 07$ for three eddies being advected by the boundary current, all of the fluid in the eddy core is trapped and traveling with the eddy. We therefore anticipated that the floats would remain trapped within the eddy cores until the cores disintegrated.

\section{c. Mooring instrumentation}

The mooring (Fig. 2) included an array of eight Aanderaa RCM-11 current meter instruments and nine Seabird SBE-37 MicroCATs from 100- to 3000-m depth and two SALP cages with their own pressure and temperature recording devices. The SALP cages, the "master" at 511- and the "slave" at 518-m depth, contained six bays each and were loaded with profiling APEX. The mooring was designed to be less stiff than a traditional mooring by using less flotation. This was done to enhance the dips in pressure caused by the passage of eddies so that this information could be utilized by the SALP controller to identify when the SALP cage was in an eddy. Details of instrumentation, quality control, calibration, and gridding may be found in the technical report by Furey et al. (2013).

\section{d. SALP design adaptation}

The prototype SALP designed by Fratantoni (2013) can be deployed inline on a conventional subsurface mooring at any depth up to $2000 \mathrm{~m}$. It is designed to hold eight floats with burn-wire controlled clamps. Individual floats can be released when data from other mooring sensors meet user-defined criteria. Communication between mooring sensors and the SALP is accomplished using acoustic modems, as opposed to cable to cable, to avoid potential cable and connector failures. Acoustic, rather than conductive, modems were used to allow for communication with a broad spectrum of instruments, such as would be found in an Ocean Observatories Initiative (OOI) global site system. [The reader is referred to Fratantoni (2013) for more information on SALP design.] The field-tested SALP held surface 


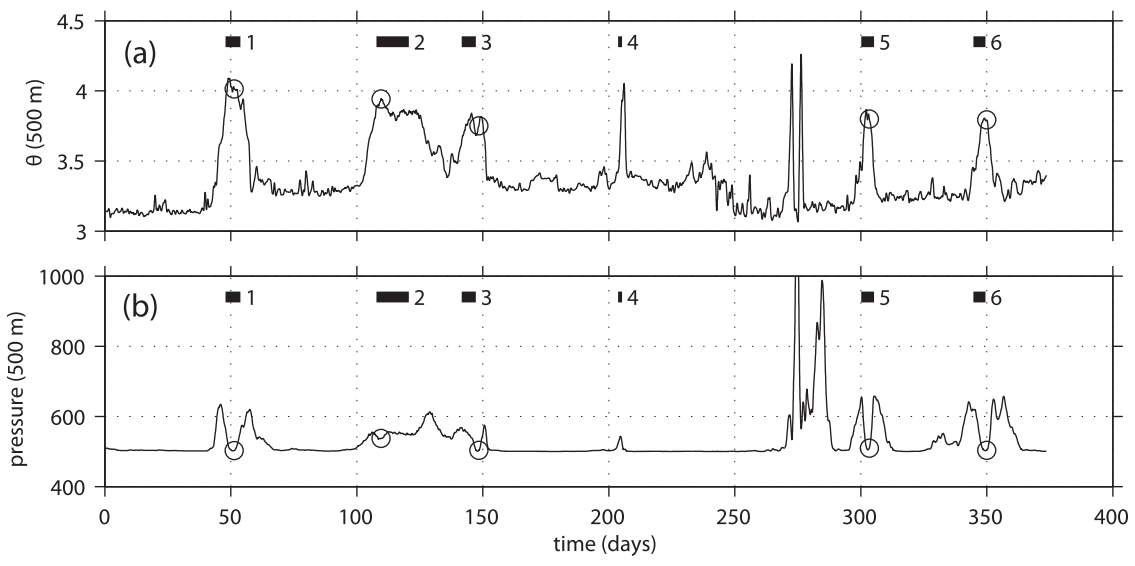

FIG. 5. Results from a test of the preliminary float release algorithm on the Bravo mooring data. (a) $\theta$ and (b) pressure at the 500-m instrument for 1 year during 1998-99. Numbered horizontal bars indicate Irminger Ring events as identified by L03. Open circles show hypothetical float releases based on the preliminary algorithm.

drifters and released them based on full water column information.

In our application, the SALP cage was modified to hold six floats that presented a significantly smaller cross-sectional area than the prototype SALP, thereby reducing excessive drag on the mooring. Since we intended to use only temperature and pressure information at the SALP depth to detect the passage of a ring, the multiple-sensor communication system on the prototype SALP was replaced with single temperature and pressure modules mounted on each SALP frame. The SALP frames were interconnected with a communication cable in order to keep track of the number of floats that had been released. The two frames were designed to work independently in the event that communication between the frames was lost.

\section{e. SALP algorithm}

The algorithm encoded in the SALP controller used a 48-h time-lagged boxcar mean temperature and pressure to decide when to trigger a burn wire, which would subsequently open a carousel bay and release a float into a passing anticyclone. Hereafter, "mean" will refer to a time-lagged mean, where the last point of the filter window is at time $T=0$, unless specified otherwise. This is used in testing because release decisions are made as the instruments record data; no forecasting is possible, so the filter windows are not able to be centered at time $T=0$ but rather must end at time $T=0$. The (time lagged) mean was used to filter out the effects of tides and other small perturbations in the temperature and pressure time series. Specifically, the algorithm was designed to release a float when at the SALP depth 1) the mean temperature exceeded $4.6^{\circ} \mathrm{C}, 2$ ) the mean pressure was 10 dbar less than the recent maximum mean pressure, and 3) the slope of the mean pressure changed sign from negative to positive. These criteria were designed to identify the following eddy characteristics: 1) the warm eddy core, 2) the pressure indicated that the first eddy velocity maximum (leading edge) had passed over the mooring, and 3) that the eddy was positioned just past the eddy center (i.e., just after the velocity/pressure minimum inside the eddy core) at the start of the second pressure peak. If the SALP launch criteria were met and an APEX was released, a lockout period was enforced, and no other floats were permitted to release for the next 20 days.

This algorithm was successfully tested on mooring data from the Bravo site (Fig. 5, location shown in Fig. 1), with the temperature criteria relaxed to $3.6^{\circ} \mathrm{C}$ to account for the cooler temperature of older IRs at the Bravo site. The circle marks on the temperature (Fig. 5a) and pressure (Fig. 5b) records indicate release points. IRs identified by $\mathrm{L} 03$ based on data from the full water column are marked 1 through 6 , and the release algorithm applied on the 500-m instrument data only identified IRs $1-3,5$, and 6 . Bravo eddy 4 was a "skirt": the eddy did not pass directly over the mooring, and the pressure sensor did not record a double dip, so the algorithm did not signal for a float release.

As this was the first implementation of this type of SALP platform and algorithm, the temperature-pressure (hereafter TE-PR) algorithm was modified to be more cautious: the goal was to have no floats left in the cages in the event that no or few eddies passed over the mooring. Floats were released on the TE-PR criteria outlined above until day 240 of the 2 -yr deployment. At this point the criteria changed to temperature only 
TABLE 1. Summary of SALP controller releases and APEX deployments.

\begin{tabular}{|c|c|c|c|c|c|c|c|}
\hline Day no. & Date & Float serial no. & Master & Slave & $\begin{array}{l}\text { Release } \\
\text { type }\end{array}$ & $\begin{array}{l}\text { Release } \\
\text { in eddy }\end{array}$ & Comment \\
\hline \multicolumn{8}{|c|}{ Day 1: Initially set to $\mathrm{T}-\mathrm{P}$ criteria to release. } \\
\hline 73 & 8 Dec 2007 & 5266 & $\sqrt{ }$ & & $\mathrm{T}-\mathrm{P}$ & No & $\begin{array}{l}\text { Released } \sim 10 \text { days after eddy at new } \\
\text { pressure displacement. }\end{array}$ \\
\hline 131 & 4 Feb 2008 & 5272 & $\sqrt{ }$ & & $\mathrm{T}-\mathrm{P}$ & No & $\begin{array}{l}\text { Subsurface warm anomaly, minimal } \\
\text { pressure displacement. }\end{array}$ \\
\hline 179 & 23 Mar 2008 & 5264 & & $\sqrt{ }$ & Timed & No & $\begin{array}{l}\text { Minimal warm anomaly, minimal } \\
\text { displacement; timed slave release. }\end{array}$ \\
\hline \multicolumn{8}{|c|}{ Day 240: Switch to T-only criterion for release. } \\
\hline 252 & 4 Jun 2008 & 5271 & $\sqrt{ }$ & & T-only & Yes & $\begin{array}{l}\text { Successful, released in center before second } \\
V_{\max } \text {. }\end{array}$ \\
\hline 319 & 10 Aug 2008 & $5270 / \varnothing$ & $\sqrt{ }$ & & T-only & Yes & $\begin{array}{l}\text { Successful, released in edge of core after second } \\
V_{\max } \text {; float jammed after wire burned. }\end{array}$ \\
\hline \multicolumn{8}{|c|}{ Day 365: Carousels become independent; switch to T-P criteria to release. } \\
\hline 459 & 28 Dec 2008 & 5269 and 5261 & $\sqrt{ }$ & $\sqrt{ }$ & $\mathrm{T}-\mathrm{P}$ & Yes & Successful, released near second $V_{\max }$. \\
\hline 528 & 7 Mar 2009 & 5265 and 5267 & $\sqrt{ }$ & $\sqrt{ }$ & $\mathrm{T}-\mathrm{P}$ & No & Long period of subsurface warm anomalies. \\
\hline 599 & 17 May 2009 & 5268 & & $\sqrt{ }$ & Timed & No & $\begin{array}{l}\text { Float failed to check in after first profile; } \\
\text { minimal warm anomaly, minimal } \\
\text { displacement. }\end{array}$ \\
\hline 660 & 17 Jul 2009 & $\varnothing$ & $\sqrt{ }$ & & Timed & No & $\begin{array}{l}\text { Minimal warm anomaly, minimal displacement; } \\
\text { timed master release but no floats left in } \\
\text { master carousel. }\end{array}$ \\
\hline 665 & 22 Jul 2009 & 5262 & & $\sqrt{ }$ & Timed & No & As day $660 ;$ timed slave release. \\
\hline 705 & 31 Aug 2009 & $\varnothing$ & $\sqrt{ }$ & $\sqrt{ }$ & $\mathrm{T}-\mathrm{P}$ & Yes & $\begin{array}{l}\text { Released on edge of center, before } V_{\max } ; \text { no } \\
\text { floats left in master or slave carousel. }\end{array}$ \\
\hline 730 & 26 Sep 2009 & 5270 & $\sqrt{ }$ & & Ship & Yes & $\begin{array}{l}\text { This float was stuck in carousel, recovered } \\
\text { with the mooring, and launched from ship at } \\
\text { mooring site. }\end{array}$ \\
\hline
\end{tabular}

(TE-only), where a float would be released if the 2-day mean was above the stricter cutoff of $4.8^{\circ} \mathrm{C}$, while no pressure information was used. At day 365 the SALP cages, which had been working in tandem, became independent. Independent operation allows two floats, one from each carousel to seed ocean-met criteria at the same time. This change was made in the event that many floats were left in both the master and slave cages, so that all floats would have a chance to release based on oceanographic conditions before the mooring was recovered. Also at day 365, the release criteria reverted from TE-only to TE-PR, as described above. Concurrent with the oceanic criteria releases, there were timed releases scheduled at days 180 and 600 . After day 600, any remaining floats were released every 60 days from the master or 60 days with a 5-day offset from the slave. The 20-day lockout was not used on timed releases. Details of the float releases are recorded in Table 1.

\section{Eddy observations and SALP releases}

\section{a. Mooring observations}

Figure 6 shows the 2-yr records for $\theta$, practical salinity, and $u$ - and $v$-velocities recorded by the mooring instruments. Broadly, the mooring data show three layers: the upper (100-800 m) salty and warm Irminger water, the intermediate (800-1500 $\mathrm{m}$ ) fresher and cooler Labrador Sea Water, and the deep $(>1500 \mathrm{~m})$, more saline Iceland-Scotland Overflow Water/Northeast Atlantic Deep Water. Punctuating the mooring record are warm and salty events in the 100- to 800-m depth range lasting a few days. In some cases, the $u$ - and $v$-velocity fields show full water column velocity reversals during these warm and saline events, some of which (black vertical lines, E1-E12, Fig. 6) are the 12 most robust anticyclones passing over the mooring site (DJ).

To identify anticyclones in the mooring records, we chose relatively warm and salty anomalies in the depth range of $300-800 \mathrm{~m}$ that also had a velocity signature consistent with a passing eddy (DJ). One example of an IR (or BCE) in this mooring record (eddy E5 in Fig. 6) is detailed in Fig. 7. In this example, the contours of temperature and salinity show a bowl-shaped anomaly of water warmer than $4.6^{\circ} \mathrm{C}$ and, in this case, more saline than $34.88 \mathrm{psu}$. These properties fall between IR properties found at Bravo, $\theta \cong 3-4.15^{\circ} \mathrm{C}$ and $S \cong 34.85 \mathrm{psu}$ (L03), and near the formation region, $\theta \cong 4.6-5.2^{\circ} \mathrm{C}$ and $S \cong 34.9$ (H07). The line marking the time the center of the eddy passed over the mooring (thick black line at 
day 0, Fig. 7) is defined as the location of maximum (downward) isopycnal displacement, using the 27.7- $\sigma_{0}$ isopycnal (white line, Fig. 7). The $u$ - and $v$-velocity signatures indicate that the anticyclone is traveling from west to east toward the Greenland slope and that the mooring is south of the center of the anticyclone.

There were 12 anticyclones of similar clarity found in the 2-yr mooring record (Fig. 6, black lines). Further discussion of the eddy characteristics, transport, seasonal variability, and heat and salt content from this mooring data may be found in DJ.

\section{b. Description of SALP APEX releases}

The 11 APEX were deployed in the Labrador Sea at the mooring site (Fig. 1). One APEX was launched from the ship in the central Labrador Sea before the mooring deployment. At mooring deployment, six APEX were loaded into in the master carousel and five APEX in the slave carousel. The SALP controller signaled to release the APEX at intervals defined by TE-PR criteria, TEonly criteria, or timed release (Fig. 6, white dashed lines), as described in section 2e. After the release in March 2009, the master carousel was empty; so, although the SALPs were working in tandem at that time, only single floats were released from the slave carousel. The details of each float release are listed in Table 2. The carousel mechanism worked exactly as designed, with the exception of one float (10 August 2008, serial number 5270; Table 2; Fig. 6), which jammed in the carousel after the release wire was burned. The SALP controller recorded this as a successful release. This float was recovered with the carousel during the mooring recovery in September 2009 and launched off the side of the ship at the mooring site, serendipitously, into a passing anticyclone.

The mismatch between when anticyclones passed over the mooring site (black lines, Fig. 6) and when the SALP signaled to release APEX based on oceanographic criteria (dashed white lines marked TP for temperature-pressure criteria or TO for temperatureonly criteria, Fig. 6) is clear. Out of the 11 SALP release events, 7 were triggered by oceanographic criteria: 5 by TE-PR criteria and 2 by TE-only criteria. These release events were only partly successful at launching APEX into passing eddies. Four ocean-based releases were in or near actual eddies, three were not. Conversely, eight robust eddies were missed by the controller algorithm. Of the four successful releases, one was when float 5270 jammed and a second was after the carousels were empty, so in both cases no APEX was released. Although the algorithm worked well when tested on the Bravo data, it was not as successful at tagging the passing anticyclones at this mooring site, which was closer to the formation region of the IRs. We will discuss the causes of these results later.

\section{c. APEX retention in eddies}

Even when successfully released into the eddy core, the APEX tracked with the eddy for a shorter time than anticipated. Two examples of APEX placement at release, a dual release into eddy E10, is shown in Fig. 8. A simulated release based on an improved release algorithm (Fig. 8, triangle marker; see section 5 for explanation) is plotted at $300 \mathrm{dbar}$ to illustrate the intended park pressure, along with the SALP carousel position at about 500 dbar (black horizontal line). The eddy center is drawn as the vertical dashed line. All APEX initially settled at a park depth that was at least 300 dbar deeper than anticipated, or $15 \mathrm{~g}$ too heavy, when they were released from their dispensers. Possible reasons include ballasting errors, incorrect piston position settings during ballasting, additional mass added after ballasting was complete, or biofouling while the floats were in their dispensers. Biofouling was ruled out: the first APEX was launched before the mooring was deployed and was also over pressure by $300 \mathrm{dbar}$. It remains unclear what caused the APEX to initially park too deep. The time series of park pressure versus time are also plotted in Fig. 8 (black dots). The APEX checks its pressure hourly and automatically adjusts its ballast if three consecutive pressure measurements are not within range of the programmed park pressure. Thus, every $3 \mathrm{~h}$ the APEX adjusts to shallower depth by about $20 \mathrm{dbar}$ or one pressure count (Swift 2007). This resulted in an average adjustment period of 2.75 days (ranging between 2.33 and 3.07 days).

The maximum azimuthal velocity at the initial depth of the APEX in eddy E10 (700 and 800 dbar) is between 15 and $20 \mathrm{~cm} \mathrm{~s}^{-1}$. These velocities are weaker than at $300 \mathrm{dbar}$, where the maximum azimuthal velocity was $\sim 35-40 \mathrm{~cm} \mathrm{~s}^{-1}$. Propagation or background velocity for this eddy is estimated to be $14 \mathrm{~cm} \mathrm{~s}^{-1}$ (DJ). A Gaussian eddy model tuned to this particular eddy shows that the APEX had very little chance of retention when the eddy azimuthal velocity was close to the background velocity (e.g., at 700 or $800 \mathrm{dbar}$ ). In contrast, at $300 \mathrm{dbar}$ the stronger azimuthal velocities result in almost all of the fluid inside the eddy radius being trapped. The floats would have likely been retained if the floats had been seeded inside the eddy core at $300 \mathrm{dbar}$.

\section{Release algorithm evaluation and improvement}

\section{a. Test of controller algorithm with mooring data}

The first step in determining what caused the mismatch between the passage of eddies and float releases 


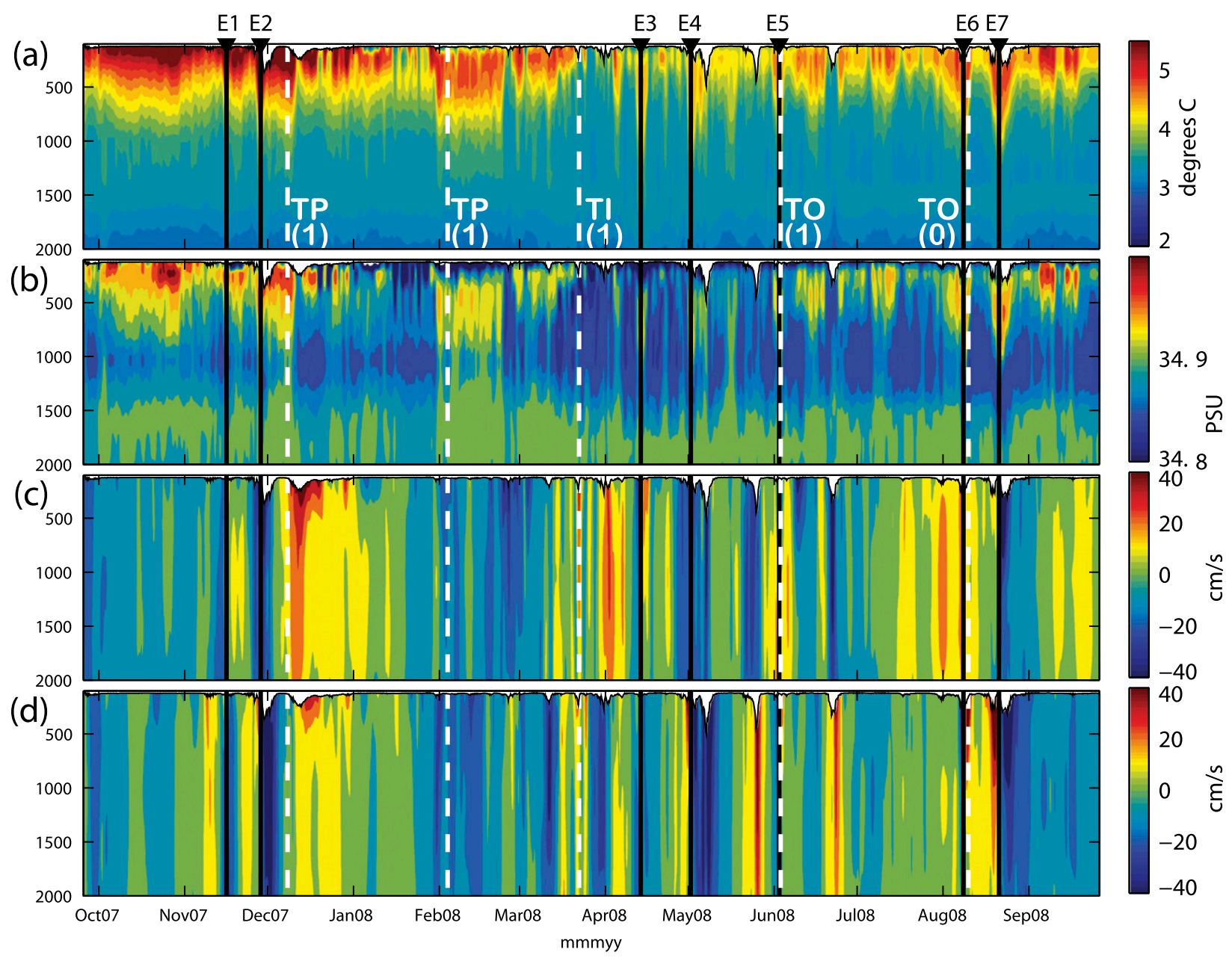

FIG. 6. The (a) $\theta$, (b) practical salinity, and (c) $u$ - and (d) $v$-velocity records for the 2-yr period September 2007-September 2009. The record has been divided into 1-yr segments: September 2007-08 and September 2008-09. The 12 most robust IRs are marked with a black vertical line topped with a black triangle and labeled E1 through E12. SALP releases are marked with white dashed lines and annotated as follows: SH, launched off ship; TP, launched by temperature and pressure criteria; TO, launched by temperature criterion only; and TI, timed release. The number of APEX actually released is noted in parentheses below the launch type.

was to run the release algorithm on the SALP full record temperature and pressure data, with the TE-PR criteria dictating all APEX releases, to determine how well the original algorithm (described in section 2e) identified eddies. The SALP pressure and temperature data, the time of the SALP controller TE-PR releases, and the 12 subjectively identified anticyclones (from DJ) are shown in Fig. 9. After examining each of the 12 robust eddies, we determined that a good initial estimate of the average peak speed to peak speed time window to be about 2 days in length. This time window is illustrated in Fig. 7 by thin vertical black lines on either side of the eddy center. We will define an SALP release within $\pm 24 \mathrm{~h}$ of the eddy center as a "positive release" and, conversely, an SALP release outside of the eddy $\pm 24-h$ window as a "negative release." In this test, and all subsequent testing described below, we ran the algorithm as though collecting data in real time. All averaging performed when testing the algorithms was done using $T$ (length of data stream - averaging window length): $T$ (length of data stream), where $T$ is time.

The TE-PR algorithm used in the field would have triggered the release of seven APEX over the 2-yr deployment period (dark green lines, Fig. 9). Four of those releases would have been near eddies subjectively identified from all the mooring data (eddies E5, E6, E10, and E12), but only two of these four releases would have been positive releases (eddies E5 and E12; Fig. 9). The remaining three of the seven APEX releases were not released near eddies. Furthermore, eight eddies were missed altogether for reasons that will be explored in detail below. In one of these cases (E7), the eddy was 


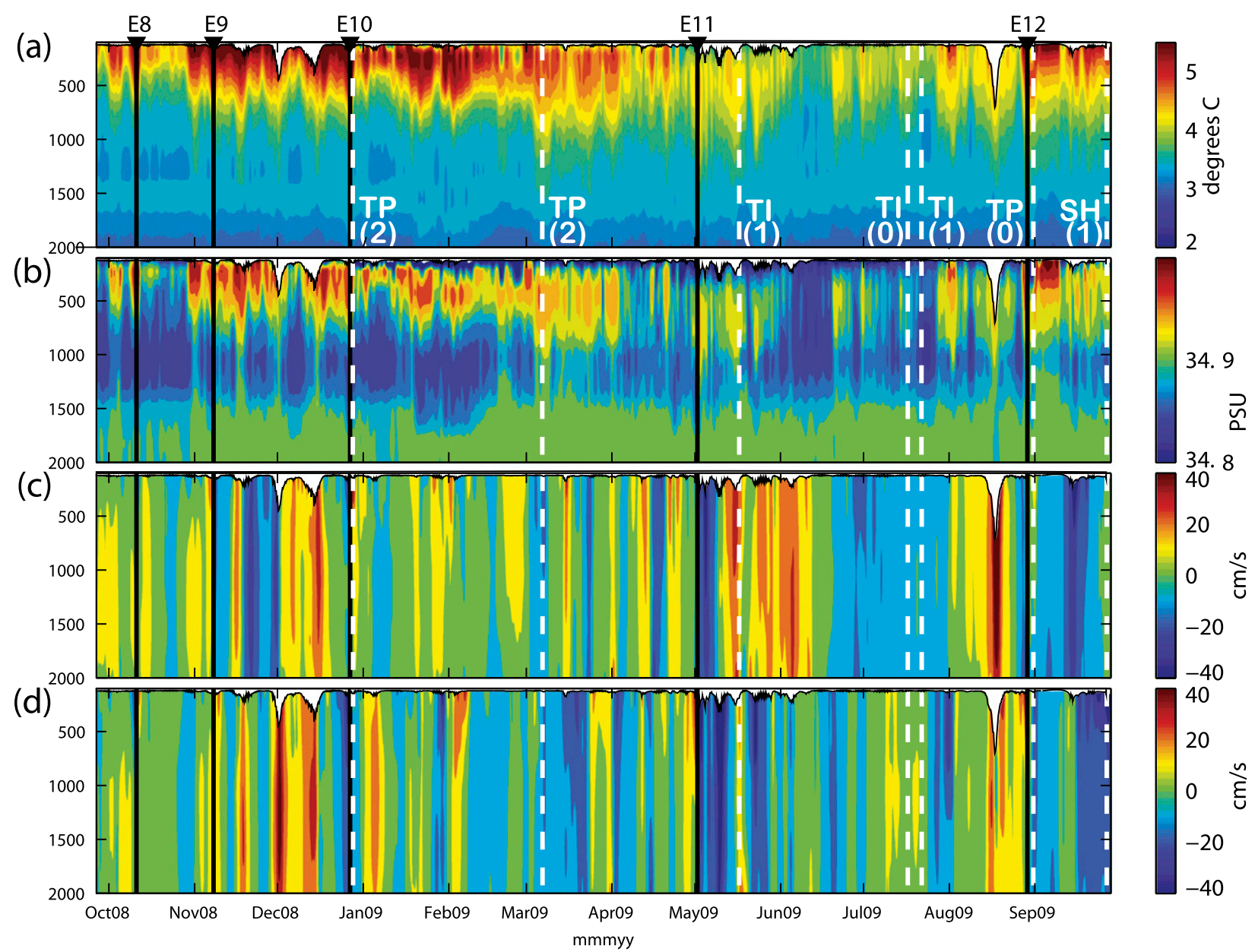

FIG. 6. (Continued)

missed because it passed the mooring less than 20 days after the previous float release and the release was "locked out" by the algorithm (light green patches after each APEX release). Two other eddies (E1 and E8) did not have a double-dip-shaped pressure record and were missed because the TE-PR algorithm required this pressure form as a criterion for release.

\section{b. Three SALP release case studies}

Examples of three types of release events, a positive release, a negative release within hours of a passing eddy, and a negative release not near an eddy, are depicted in Fig. 10. The signal to release a float is contingent upon the satisfaction of the pressure (top row) and temperature (middle row) criteria and the lockout not being enabled (bottom row, dashed line; value near 1 is open, near zero is closed). When all three criteria are satisfied, the float is released (x's and green vertical lines). In the case of the positive release (left column), the release was triggered at the tail end of the eddy core (gray patch). In the case of the near-eddy negative release (middle column), the release was triggered a few hours after the eddy core had passed by the mooring, and in the negative release (right column), there was no eddy present but a long period of ambient water above $4.6^{\circ} \mathrm{C}$, to be addressed further below.

The lockout state is binary-either on or off-and, in all three cases in Fig. 10, the lockout was not enabled. The temperature criterion was also straight forward: the 48-h running-mean temperature had to be above the temperature cutoff. This allowed continuous windows of time when the temperature criterion was satisfied, although the low-pass filtering shifts the release period toward the trailing half of the warm core.

Satisfying the pressure criteria was more complex. Measured pressure (PR), mean pressure (PRmean), and maximum mean pressure (PRmax) are plotted in Fig. 10 (top row) for the three case studies. The maximum mean pressure was calculated as the maximum value of mean pressure while the lockout was "open," or set to 1, after the subsequent eddy passage and lockout period. The pressure criteria were designed for a double-dip pressure record structure of the passing eddy. Two criteria 


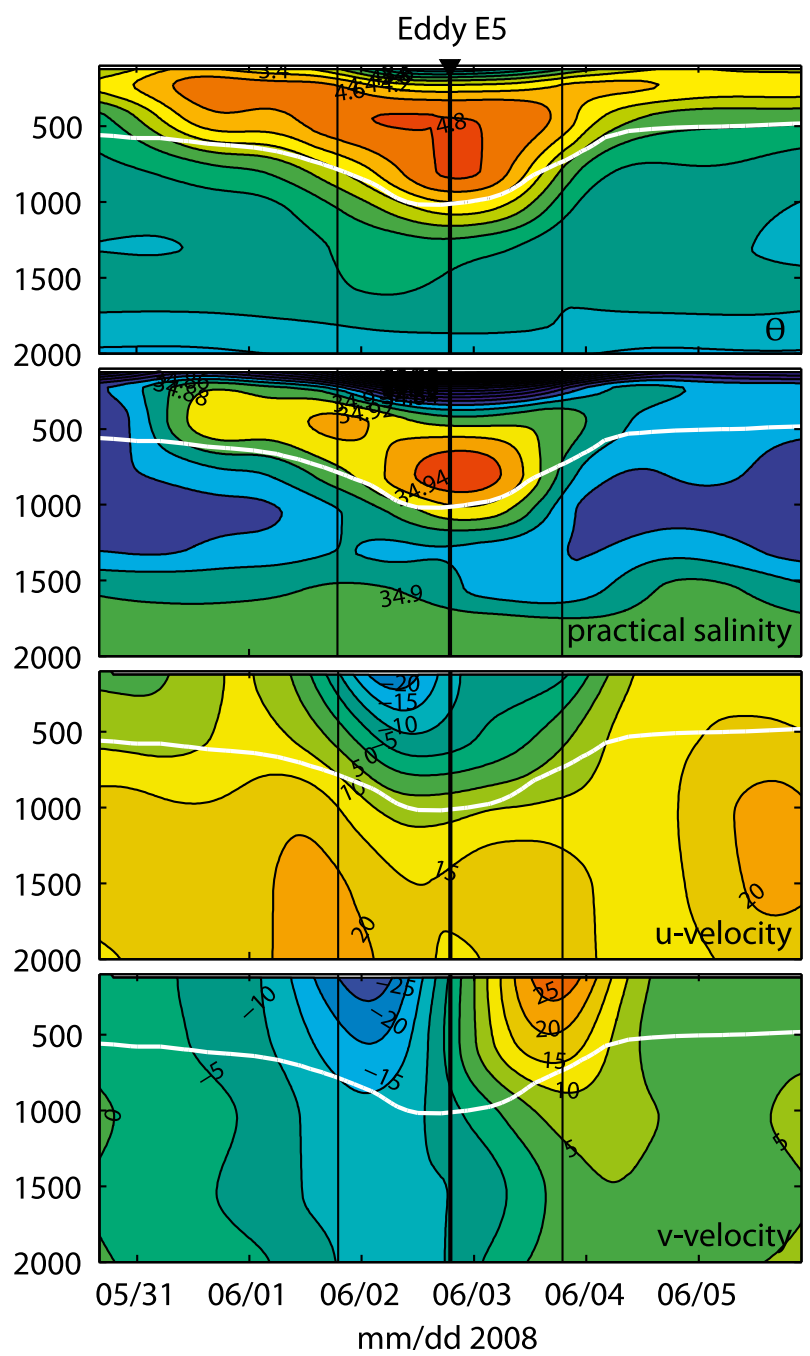

FIG. 7. One example of an IR found in the mooring record (Fig. 6, eddy E5, June 2008). Top to bottom: $\theta$, practical salinity, $u$ velocity, and $v$ velocity. The center of the eddy (bold black line) is calculated as the point of maximum (downward) displacement of the 27.7- $\sigma_{0}$ isopycnal (white line). The thin lines $24 \mathrm{~h}$ before and after the eddy center mark the approximate eddy core in time.

were required to be satisfied: the mean pressure had to be 10 dbar less than the maximum mean pressure (past the first peak in the double-dip-shaped pressure record) and the mean pressure curvature had to be positive (mooring positioned to go down a second time). When both requirements were satisfied, the pressure criteria were met (PRgo; Fig. 10, bottom row).

In the cases of positive release (left column, Fig. 10) and negative release not near an eddy (right column), the value of maximum mean pressure does not reflect the local pressure record, and the value of PRmax is always greater than the value of PRmean. If mean pressure excursions increased, but no float was released and lockout remained open, mean pressure could be much greater than pressure excursions at a subsequent eddy (see pressure dips in May 2008 before burn wire at E5 triggered; Fig. 8). The algorithm is effectively functioning as one based on temperature only in these two cases. In the case for the near-eddy negative release (center column), the 48-h mean pressure lags the doubledip pressure record enough to make SALP release lag the actual eddy and miss the core.

While the release algorithm worked well for identifying eddies in the Bravo mooring data, environmental conditions at our mooring site were different enough to cause the algorithm to be not well tuned. Three factors are already clear from the examination of the original algorithm: 1) the 20-day lockout period prevented valid APEX releases, 2) the choice of a 48-h averaging window was too long compared to the transit time of eddies past this mooring site, and 3) the calculation of maximum mean pressure was not always relevant to the local conditions.

\section{c. Lockout adjustment}

The 20-day lockout period after each float release was intended to suppress the release of more than one APEX into the same eddy. This time window should be based on the typical radius and translation speed of the passing eddies and possibly on the number of days between eddy events. Of the 12 eddies identified in the mooring data (DJ), the minimum time between eddy centers was 12 days. These mooring data show that although eddy cores typically passed by the mooring in $48 \mathrm{~h}$, some eddies were either wider and/or slower to pass; the slowest took about 5.5 days to completely pass the mooring (DJ). A better choice for the maximum lockout window for this mooring record is between 3 and 9 days. When an 8-day lockout period is applied to the controller algorithm, there is a positive release at eddy E7 (which was missed in practice because of lockout). Testing of the controller algorithm with variable lockouts shows that the positive release result is the same within a window of 3-9 days.

\section{d. Eddy translation speed and averaging window}

The near-eddy negative release example in Fig. 10 (middle column) illustrates that the 48-h averaging window used to filter high-frequency pressure fluctuations was too long for the eddies that intersected the mooring. Although this window length had worked well on the Bravo mooring data, the eddies at this mooring site (to the northeast and presumably closer to the generation site) were smaller and/or faster than the older eddies at Bravo (the shortest eddy passage time at the IR mooring site was $36.5 \mathrm{~h}$; DJ). Figure 11 shows the effect of 


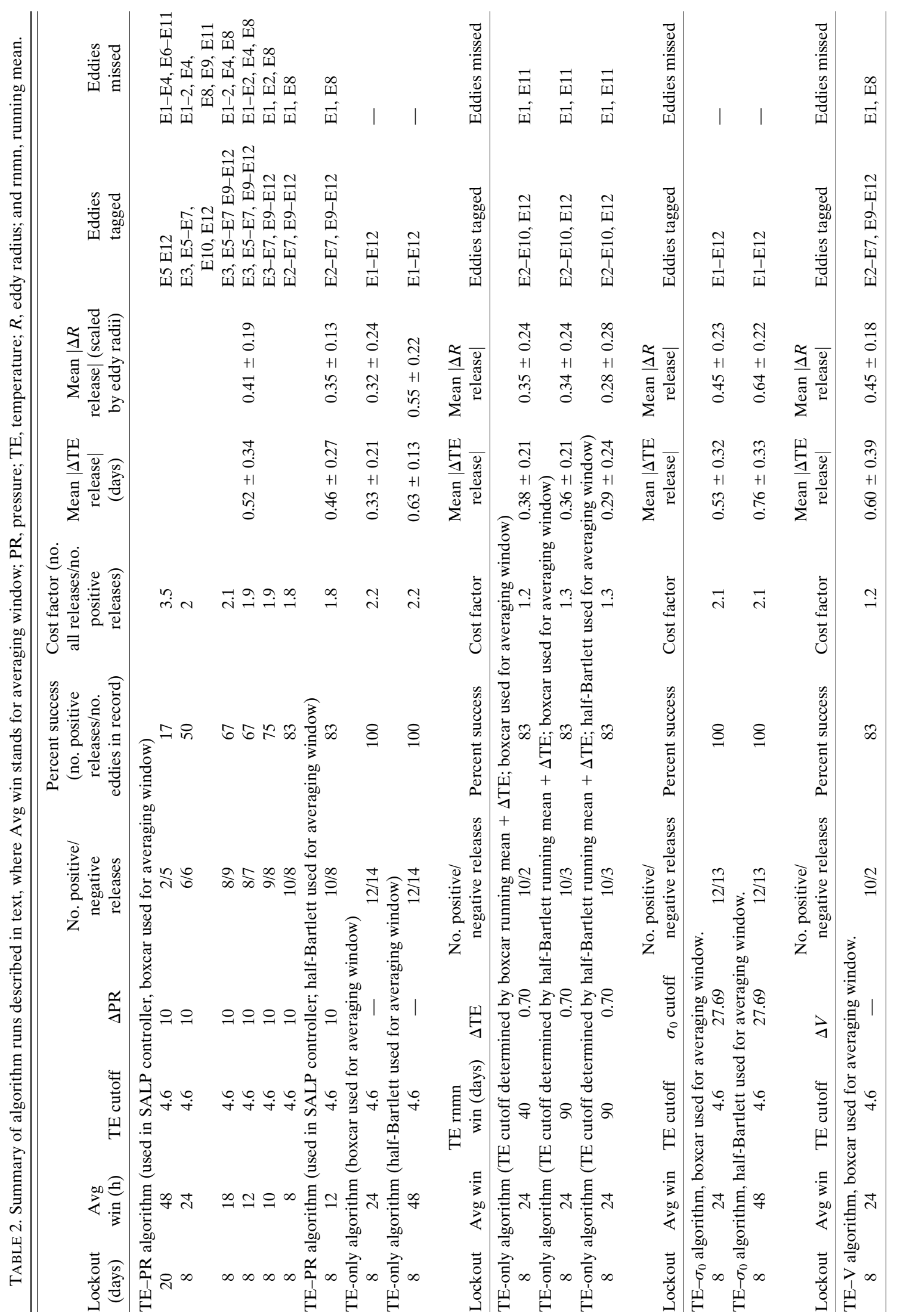




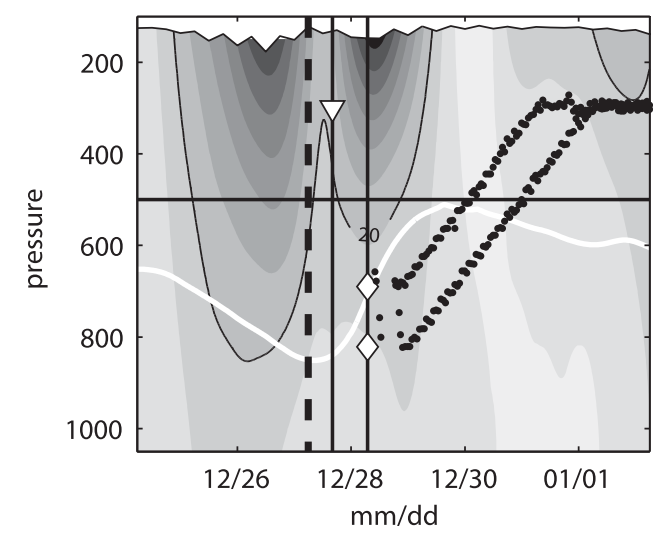

FIG. 8. Two APEX (5261 and 5269) depths and positions in time (diamond symbols) at release for eddy E10, plotted on speed recorded by the mooring. Speed is shaded every $5 \mathrm{~cm} \mathrm{~s}^{-1}$, with the $20 \mathrm{~cm} \mathrm{~s}^{-1}$ isotach contoured. The eddy center is marked with a vertical dashed line. In addition to the actual APEX releases, one optimized release position for the TE-vary algorithm (see text, section 5) is plotted at the desired park pressure of $300 \mathrm{dbar}$. The SALP cages were nominally positioned at $\sim 500 \mathrm{~m}$, marked by the thin black horizontal line. The 27.7- $\sigma_{0}$ isopycnal has been drawn as a white line. APEX park depth adjustment positions vs time are plotted as black dots, although once the floats are released from the SALP cages, the APEX is no longer necessarily in water mapped by the speed contours.

different filter windows on the data: $48 \mathrm{~h}$ (bold black line), $24 \mathrm{~h}$ (red line), and $12 \mathrm{~h}$ (green line). With the shorter ( 24 or $12 \mathrm{~h}$ ) averaging windows, the double-dip shape is retained and the tidal oscillations are still suppressed. With an 8-h averaging window, there are 10 positive releases, which is the maximum number of positive releases possible with this algorithm. The greater number of positive release also yields a greater number of negative releases, which makes it inefficient. The total for the TEPR algorithm with optimized averaging window $(8 \mathrm{~h})$ and lockout ( 8 day) parameters are 10 positive and 8 negative releases.

\section{e. Temperature cutoff}

The anticyclone temperatures, smoothed using a 24-h (time lagged) mean, are at or above $4.6^{\circ} \mathrm{C}$ at the SALP depth (Fig. 12). All anticyclones have temperatures that fall above the temperature cutoff of $4.6^{\circ} \mathrm{C}$ (horizontal line); therefore, this was an appropriate choice for anticyclone identification in this region. We note here, though, that there are periods of high temperatures that are not related to passing eddies that caused negative releases (Fig. 10, right column).

\section{f. Vertical mooring displacement}

The eddies recorded by the SALP instruments did not usually have the clean double-dip shape presented in
Fig. 4c, likely because this site is close to the eddy formation site and the eddies might not have reached a steady state. The variable shape of pressure records can be seen in Fig. 12a. The dependence of the controller algorithm to a double-dip pressure signature results in some missed eddies no matter the tuning of the algorithm, specifically eddies E1 and E8 (bold lines, Fig. 12), which have flat pressure records due to weak/shallow azimuthal velocities.

\section{Algorithm modifications and results}

Using the other mooring instrument data, we modify the original SALP algorithm to see if we can improve results. Our constraint was to find the best possible algorithm using a single point measurement at the SALP depth. The goal is to have a high number of positive releases, while minimizing negative releases (wasted floats). We define the number of positive releases/total number of eddies as the algorithm's "success rate." We define the total number of positive plus negative releases/positive releases (or the total number of floats released/number of floats released into eddies) as the "cost factor." The best algorithm will have a cost factor of 1 so that each float released is successfully released into an eddy.

\section{a. Temperature-pressure (TE-PR) algorithm}

With the original SALP algorithm, the success rate was $2 / 12$, or about $17 \%$, and the cost factor was $7 / 2$, or 3.5 . With the lockout window lowered to 8 days, and the averaging window lowered to $8 \mathrm{~h}$, the success rate rises to $83 \%$ and the cost factor lowers to 1.8 . Model runs, parameters used, positive and negative release tallies, success rates, and cost factors are provided in Table 2. The shorter averaging window allows the temperature criterion to be satisfied sooner, therefore allowing the possibility of capturing the first pressure peak as an eddy passes with the pressure portion of the SALP TE-PR algorithm.

The running means used in the SALP algorithm were estimated with a boxcar window. To better capture the local peaks in the temperature and pressure data, we modified the filter to use a half-Bartlett window. (The half-Bartlett was necessary because the SALP collects data, and the algorithm runs, in real time.) This halftriangle-shaped filter enhanced the shape of the leading edge of the eddy. The best run using this kind of averaging window had a similar success and cost as the run with the boxcar window. However, the release times were slightly closer to the passage of the eddy center using the Bartlett window, with the mean release in time being 0.41 days after eddy center versus 0.52 days after eddy center using the boxcar filter (Table 2). 

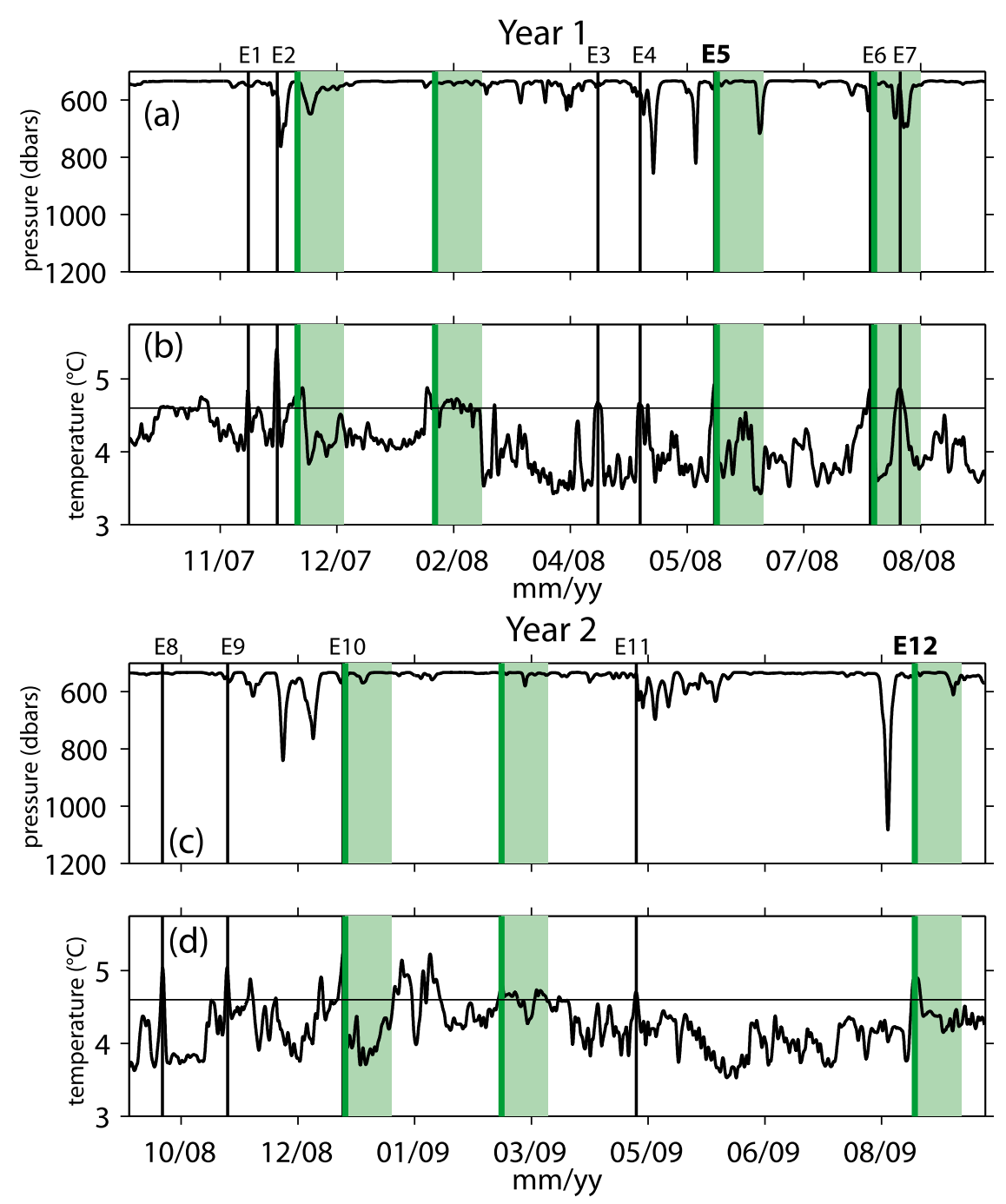

FIG. 9. SALP pressure and in situ temperature, (a),(b) September 2007-08 and (c),(d) September 2008-09, smoothed with a 40-h low-pass filter. The 12 eddies centers are drawn as black vertical lines and labeled E1 through E12. TE-PR releases using the original controller algorithm, as loaded in to the controller during the experiment, are marked as a vertical green lines, with a patch following the event marking the 20-day lockout period when no floats were allowed to release. The thin horizontal line in each temperature plot [see (b) and (d)] is at $4.6^{\circ} \mathrm{C}$, the temperature cutoff used by the SALP controller. If an eddy was successfully tagged with a positive release (see text), the eddy label is in bold.

This algorithm's (and subsequent algorithms') results are presented by plotting release times during the 2-yr mooring records (Fig. 13). This plot shows both the positive and negative release positions to give a visual presentation of which eddies were seeded and when the negative releases occurred. Figure 14 shows the positive release positions plotted relative to the eddy center, to show where different algorithms position the float relative to the core of the eddy. The eddies in this 2-yr mooring record pass the mooring in variable amounts of time, from 36.5 to $127.5 \mathrm{~h}$ (DJ). The rigid definition of a \pm 24 -h eddy window means that the relative distance of the release position in relation to the eddy radius may be poorly represented. To account for this, in Fig. 14, we also present release time scaled by the $1 / 2$ eddy time from peak to peak velocity. In both Figs. 13 and 14, the TEPR algorithm is marked by a downward-pointing triangle. Some TE-PR positive releases (Fig. 14) are near the edge of the 24-h hit window but, when scaled by eddy radius, are actually closer to the centers of individual eddies. All previous positive release, negative release, success, and cost statistics presented above, as well as the values in Table 2 (unless noted otherwise), are found using scaled eddy radii. 


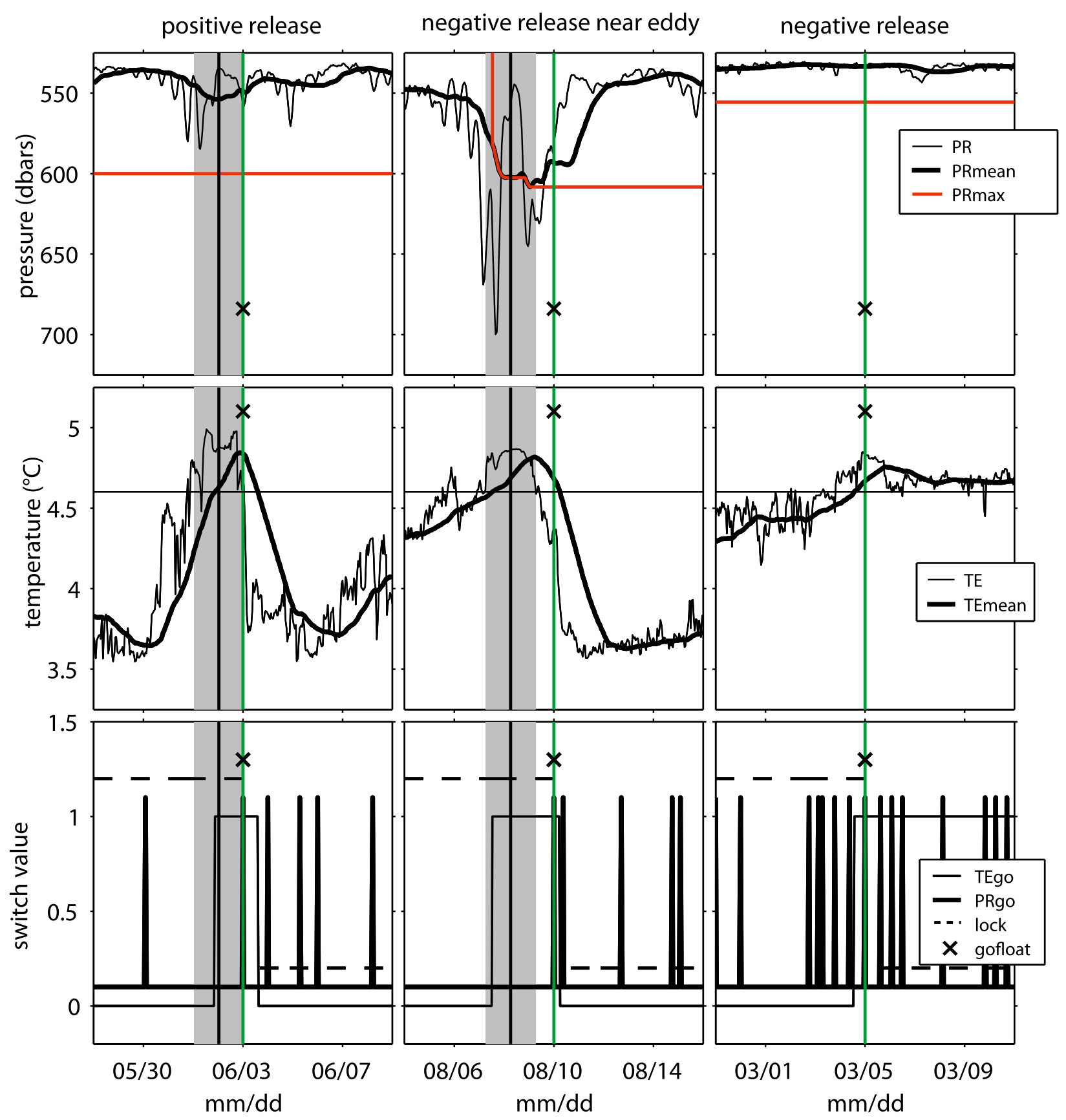

FIG. 10. Three cases of controller algorithm release: (left) a positive release, (center) a negative release just after an eddy passage, and (right) a negative release. First row shows SALP measured pressure, the 48-h running-mean pressure, and the value of PRmax (red line, see text). Second row shows SALP temperature and 48 - $\mathrm{h}$ mean temperature. The $4.6^{\circ} \mathrm{C}$ cutoff is depicted as a thin black horizontal line. Bottom row is switch values that control APEX release: TEgo, which indicated all temperature criteria are satisfied; PRgo, which indicates all pressure criteria are satisfied; lock, which indicated if lockout is in place $(0=$ locked $)$; and gofloat, which means all three criteria satisfied, so the APEX burn wire may be triggered. The $\% 1$ switch values have been offset from each other for visual clarity. On all subplots, the green vertical line and " $\mathrm{x}$ " marker show the point where the burn wire is triggered. The vertical black lines and gray patches on some panels (the positive release and near-eddy negative release cases) show the center of an actual eddy and the \pm 24 -h window surrounding that center point.

\section{b. Temperature-only algorithm}

A modified TE-only algorithm, specifically where the mean temperature was required to exceed a fixed temperature cutoff of $4.6^{\circ} \mathrm{C}$ and the mean temperature curvature was negative, was designed to catch warm anomalies at the center of the eddy, this curvature being evident in the eddy temperature records (Fig. 12b). 


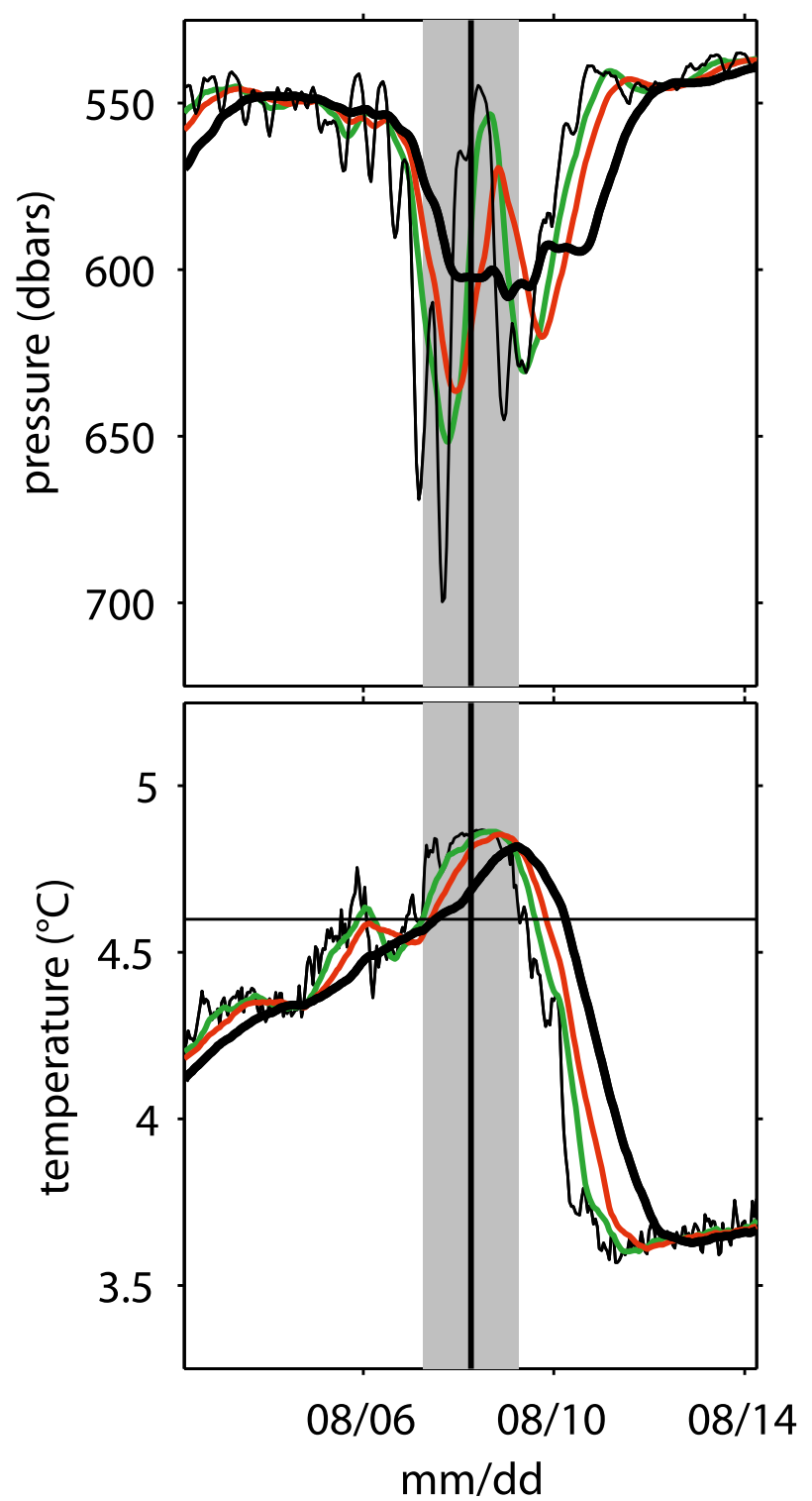

FIG. 11. SALP pressure and temperature data of an eddy showing three averaging windows created with a time-lagged boxcar filter: $48 \mathrm{~h}$ (bold black line), used in the controller algorithm; $24 \mathrm{~h}$ (red line); and $12 \mathrm{~h}$ (green line). Eddy center and \pm 24 -h window are depicted as in Figs. 10.

Without the downward curvature criterion, the releases happen too early to be embedded inside the eddy walls. This algorithm yields 12 positive releases, though there are many negative releases. The success rate is $100 \%$, but the lowest cost factor is 2.2 (Table 2). The best run of this algorithm yielded 12 positive and 14 negative releases, with similar results using the Bartlett window to average the data (circle markers in Figs. 13, 14). As mentioned earlier, there are periods of warm water greater than $4.6^{\circ} \mathrm{C}$ that are unrelated to passing eddies.

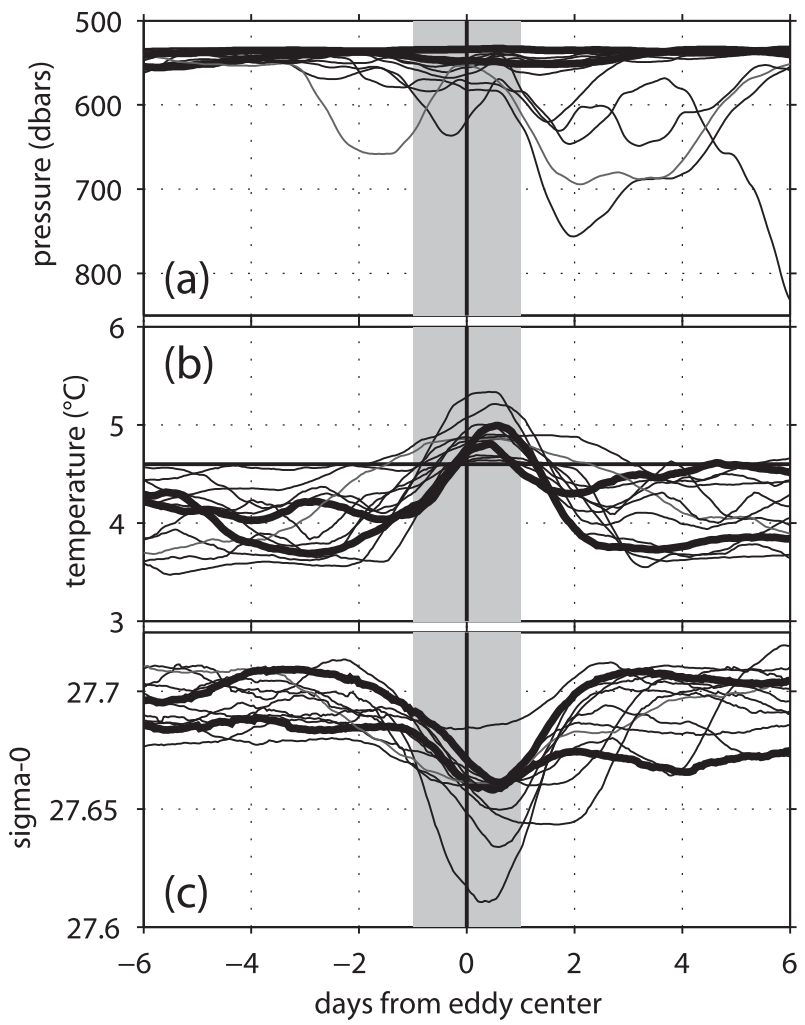

FIG. 12. The 24-h time-lagged mean (a) SALP pressure, (b) SALP temperature, and (c) $\sigma_{0}$ at the SALP pressure calculated from mooring data. These 12 eddies represent the algorithm targets. Eddy center and \pm 24 -h window are depicted as in Fig. 10 . Bold black lines in PR, TE, and $\sigma_{0}$ indicate those not able to be tagged using the TE-PR algorithm.

\section{c. Temperature-density $\left(T E-\sigma_{0}\right)$ algorithm}

Since the SALPS were attached to a mooring with sensors recording conductivity and velocity, as well as temperature, we next modified the algorithm to try to capture anticyclones based on both density interpolated to the SALP depth and temperature criteria. As seen in Fig. 12c, the density records of the eddies show a bowl-shaped isopycnal record in conjunction (and partly derived from) the downward bowl-shaped temperature record. We modified the algorithm to release a float when the mean temperature was above the cutoff, and downward sloping, in conjunction with mean density below $\sigma_{0}=27.29$ and increasing. Using a 24-h boxcar or a 48-h Bartlett averaging window yielded the best results: 12 positive and 13 negative releases or a success rate of $100 \%$ and cost of 2.1 (star symbols, Figs. 13 and 14). Including density does not lower the number of negative releases.

\section{d. Temperature with time-varying temperature cutoff (TE-vary) algorithm}

We modified the TE-only algorithm to employ a time varying temperature cutoff (TE-vary) to account for 


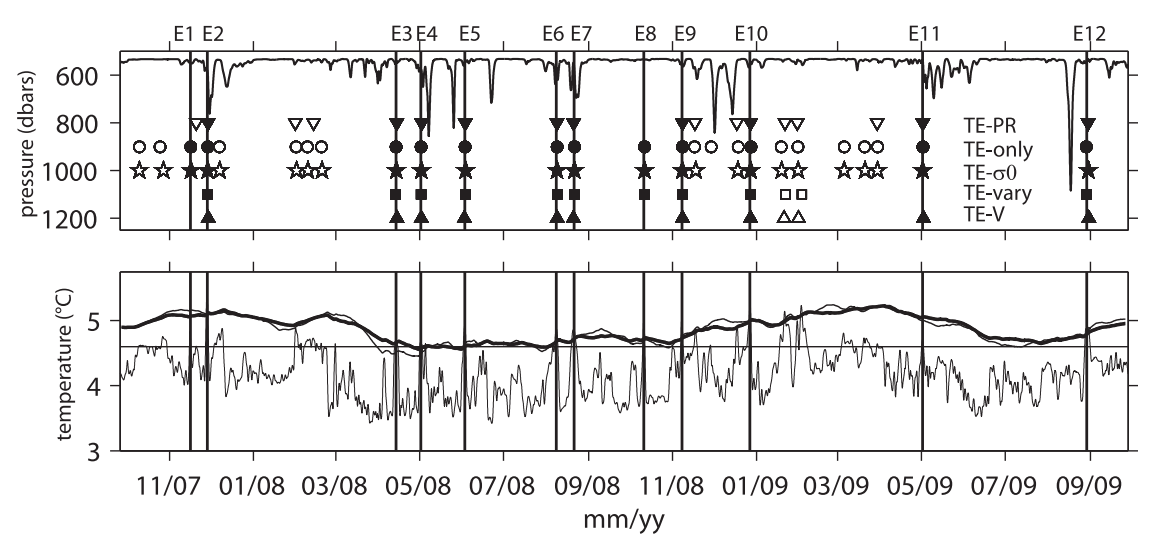

FIG. 13. The 2-yr record of SALP (top) pressure and (bottom) temperature. The time-lagged 40-day boxcar and 90-day Bartlett filtered temperature data are also plotted in the lower panel, as well as the $4.6^{\circ} \mathrm{C}$ fixed temperature cutoff. The best runs for each algorithm type are shown: downward-pointing triangle, TE-PR; circle, TE-only; star, TE- $\sigma_{0}$; square, TE-vary (in this case, 90-day running mean); and upward-pointing triangle, TE-V. If a symbol has solid fill, then the release was a positive release; if open, then a negative release.

seasonal variability in the background temperature at $500 \mathrm{~m}$ (Fig. 13; see also DJ). We ran through window lengths from 10 to 180 days, using a short-term averaging window length of $24 \mathrm{~h}$, while varying the $\Delta T$ added to the background temperature from $0.25^{\circ}$ to $0.90^{\circ} \mathrm{C}$ by $0.05^{\circ} \mathrm{C}$ increments. We also used combinations of boxcar and half-Bartlett windows in calculating both the short and long running means. The initial padding value for the running mean was $4.2^{\circ} \mathrm{C}$ : the first in situ recorded temperature value. Generally, the negative releases were reduced as the time-varying temperature cutoff became stricter (increased). The best success was found using a 40-day time-lagged boxcar averaging window, as well as a short boxcar window, and a $0.70^{\circ} \mathrm{C}$ addition to the background long-term mean temperature. The success rate in this case was $83 \%$ and the cost factor was 1.2 , with 10 positive releases and 2 negative releases (see square markers in Figs. 13, 14). The eddies missed using this algorithm were E1 and E11. These two IRs had core temperatures above $4.6^{\circ} \mathrm{C}$, but the values were not greater than the time-varying mean plus a $\Delta T$ large enough to reduce negative releases. Specifically, E1 was a shallow eddy and E11 was a cooler eddy.

\section{e. Temperature-velocity (TE-V) algorithm}

Although the TE-vary did a good job of reducing the number of waste floats, we were curious to see the effect of including velocity data in the algorithm, leaving the temperature criteria similar to the TE-only algorithm. We found the best way to incorporate velocity was to look for accelerations greater than $1 \mathrm{~cm} \mathrm{~s}^{-1} \mathrm{~h}^{-1}$ (the sampling interval of the SALP) and a corresponding $u$ - or $v$-velocity change of sign during times when the temperature criteria were satisfied. This algorithm had similar success as the TE-vary algorithm: at best, 10 positive releases and 2 negative releases or $83 \%$ success and a cost factor of 1.2 (upward pointing triangles, Figs. 13, 14). The two eddies missed were the ones also missed by the TE-PR algorithm, E1 and E8, with weak velocity signatures and negligible pressure displacement.

\section{Summary}

An autonomous device for releasing profiling floats in warm-core eddies (Irminger Rings) in the Labrador Sea was tested for 2 years during 2007-09. Electronically and mechanically, the submerged autonomous launch platform (SALP) functioned well, with 1 out of 11 floats getting jammed in the frame and not releasing properly. In contrast to this technological success, profiling floats did not get trapped in anticyclones as intended. Three primary reasons have been identified. First, the initial park pressure of the floats was too deep (i.e., below the depth of the strong azimuthal velocities associated with the eddies), and the adjustment to programmed park pressure took too long. Second, the release algorithm, which was based on running-mean temperature and pressure (as a proxy for velocity) at one depth, missed some eddies because (i) a 20-day lockout following a prior float release was in place; or (ii) the width of the averaging window for the running mean was too long, causing floats to be released at the trailing edge of an eddy or not at all. Third, the background temperature at $500 \mathrm{~m}$ varied seasonally, and some floats were released 

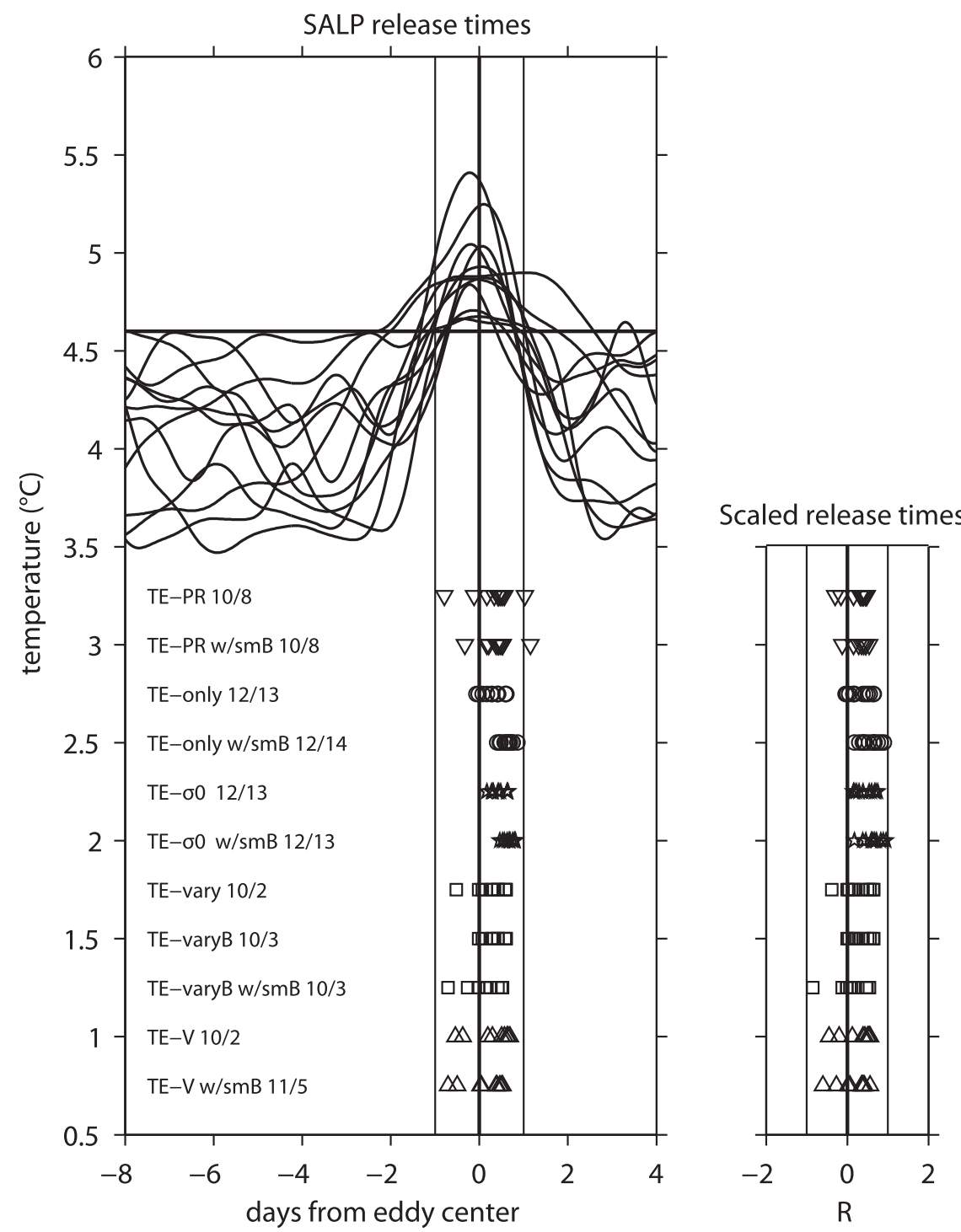

FIG. 14. The (left) 24-h low-pass time-centered SALP temperature for the 12 best eddies and release times relative to eddy center for different controller algorithms. Downward-pointing triangles, TE-PR; circles, TE-only; stars, TE- $\sigma_{0}$; squares, TE-only with long running mean; and upward-pointing triangles, TE-V. For each algorithm type, two or more examples are shown that illustrate the effect of using a boxcar vs half-Bartlett filter for the averaging window, and, in the case of the TE-vary algorithm, for the long-term running-mean filter. The w/sB, halfBartlett window was used to calculate the short-term time-lagged running mean; TE-varyB, half-Bartlett window was used to calculate the time varying temperature cutoff. The number of hits vs misses is noted to the left of each algorithm. (right) The same release data but scaled to eddy radii, which varied in width and/or translation velocity. In both plots, the positions of the release times along the temperature axis are arbitrary. The eddy center is marked by a vertical

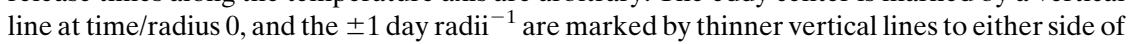
eddy center.

into warm anomalies that were not associated with eddies. Only three floats were released into eddy cores but were not retained because of deep initial park points. The anticyclones passed the IR mooring site more quickly and at shorter intervals than at the Bravo site. Furthermore, the "background" at the IR mooring site was more energetic than at Bravo, making it more difficult to pick out the IRs (or BCEs).

Several variations to the release algorithm were tested a posteriori to see how the seeding statistics could be 
improved while minimizing the number of negative releases, using the high-resolution time series records from the IR mooring instruments. It was found that an 8 -h averaging window (as opposed to the 48 - $\mathrm{h}$ window that was used) and an 8-day (as opposed to 20 days) lockout brought the success rate up from $17 \%$ (2 positive releases/ 5 negative releases) to $83 \%$ (10 positive releases/ 8 negative releases). Two eddies were not possible to catch with the TE-PR algorithm, eddies E1 and E8, because these eddies had weak velocity at $500 \mathrm{~m}$ $\left(<20 \mathrm{~cm} \mathrm{~s}^{-1}\right)$ and therefore negligible mooring blowdown. We compared release times relative to the eddy center using both half-Bartlett (or half triangle) and boxcar windows. In all algorithm configurations, the Bartlett window did not change the number of positive or negative releases. Using a Bartlett window, depending on the algorithm chosen, narrowed the time between the eddy center and when the float was released, which would improve float retention in an eddy.

Temperature alone (TE-only) worked to tag all of the 12 best eddies and so had a $100 \%$ success rate, though the cost factor was high (2.1) with 13 negative releases. Employing a time-varying running mean for the temperature cutoff reduced waste floats significantly. Using a 40-day window, and a boxcar filter for both the longand short-term running means, resulted in 10 positive and 2 negative releases or an $83 \%$ success rate and cost factor of 1.2. Using a 90-day half-Bartlett window to calculate the means brought the mean release position from 0.35 days after eddy center to 0.23 days after eddy center. The two eddies missed, E1 and E11, had a smaller temperature anomaly at $500 \mathrm{~m}$ relative to the long-term mean, below the threshold that culled negative releases.

By using the mooring salinity and velocity data, we tested how adding additional sensors to the SALP instrument would have changed the success of the experiment. We found that using a combination of temperature and density criteria had a neutral effect on the success of the modified TE-only algorithm, which is perhaps not surprising considering the IR characteristics (Fig. 12; DJ). The TE-V algorithm missed exactly the IRs the TE-PR algorithm did, E1 and E8, but with less negative releases. Using velocity, though, adds to the cost of the instrument, the possibility of instrument malfunction, and a set of assumptions about velocity and acceleration that are specific to this particular kind of eddy at this particular location. We note that the choice of averaging window is also based on assumptions of eddy size and propagation speed.

Two events tagged by all best runs of different routines (Fig. 13) were at days 485 and 497, 24 January 2009 and 5 February 2009. Those two anticyclones were surface-trapped anticyclones: the February one stronger than the January one, with velocity signature only down to $\sim 500 \mathrm{~m}$. The properties of these eddies indicate that they are IRs or BCEs that have skirted the mooring or passed by the mooring off the center of the eddy. Considering that these events are in fact anticyclones, and if a float were to be retained in the eddy if deployed offset from the eddy center, it is possible to say that both the TE-vary and the TE-V algorithms would have had a $100 \%$ success rate and more importantly a cost factor of 1.0 , although both caught 10 out of 12 of the most robust eddies.

We have found that additional sensors, specifically conductivity or velocity, are not necessary for good success releasing floats into passing eddies in this oceanographic environment. It is also not necessary to use pressure variability to successfully tag eddies. Careful considerations of eddy speed and/or size, and therefore how quickly an eddy will pass the mooring, the size of the lockout window, and temperature anomaly of the eddies, are essential to the instrument success. Although the outcome of the SALP seeding was not as successful in practice as we hoped, it was a successful first application of this modified instrument type in that the instrument worked mechanically and electronically as designed. That, along with a modified algorithm with tuned parameters, would have allowed successful tagging of IRs or BCEs using time series of environmental conditions at a single depth.

The SALP has many potential multidisciplinary applications, as discussed at length in Fratantoni (2013), including integration into the National Science Foundation (NSF) OOI global site systems of moorings. The tested adaptation of the SALP algorithm, as discussed here, is essential to this instrument's success in any application.

Acknowledgments. The authors thank David Fratantoni for generously allowing us to build upon his prototype SALP design. We would also like to thank Teresa McKee, Fiamma Straneo, Mike Spall, Rick Trask, George Tupper, Will Ostrom, John Kemp, John Lund, and the crew of the R/V Knorr (WHOI), Dana Swift (UW), and Jonathan Lilly (NWRA) for help with instruments, processing software, mooring design, expert mooring deployment, and recovery related to this experiment. This work was funded by the National Science Foundation Grant OCE-0623192.

\section{REFERENCES}

Chanut, J., B. Barnier, W. Large, L. Debreu, T. Penduff, J. M. Molines, and P. Mathiot, 2008: Mesoscale eddies in the 
Labrador Sea and their contribution to convection and restratification. J. Phys. Oceanogr., 38, 1617-1643.

Davis, R. E., J. T. Sherman, and J. Dufour, 2001: Profiling ALACEs and other advances in autonomous subsurface floats. J. Atmos. Oceanic Technol., 18, 982-993.

Eriksen, C. C., T. J. Osee, R. D. Light, T. Wen, T. W. Lehman, P. L. Sabin, J. W. Ballard, and A. M. Chiodi, 2001: Seaglider: A long-range autonomous underwater vehicle for oceanographic research. IEEE J. Oceanic Eng., 26, 424-436.

Flierl, G., 1981: Particle motions in large-amplitude wave fields. Geophys. Astrophys. Fluid Dyn., 18, 39-74.

Fratantoni, D. M., 2013: Environmentally adaptive deployment of Lagrangian instrumentation using a submerged autonomous launch platform (SALP). Mar. Tech. Soc. J., in press.

Furey, H. H., T. McKee, M. F. de Jong, P. E. Robbins, and A. S. Bower, 2013: Impact of Irminger Rings on deep convection in the Labrador Sea: Mooring instrument, cruise CTD, and APEX data report, September 2007-September 2009. WHOI Tech. Rep. WHOI-2013-05, 103 pp.

Gelderloos, R., C. A. Katsman, and S. S. Drijfhout, 2011: Assessing the roles of three eddy types in restratifying the Labrador Sea after deep convection. J. Phys. Oceanogr., 41, 2102-2119.

Hátún, H., C. C. Eriksen, and P. B. Rhines, 2007: Buoyant eddies entering the Labrador Sea observed with gliders and altimetry. J. Phys. Oceanogr., 37, 2838-2854.

Katsman, C. A., M. A. Spall, and R. S. Pickart, 2004: Boundary current eddies and their role in the restratification of the Labrador Sea. J. Phys. Oceanogr., 34, 1967-1983.
Lazier, J. R. N., 1980: Oceanographic conditions at ocean weather ship Bravo, 1964-1974. Atmos.-Ocean, 18, 227-228.

— R. Rendry, A. Clarke, I. Yashayaev, and P. Rhines, 2002: Convection and restratification in the Labrador Sea. Deep-Sea Res. I, 49, 1819-1835.

Lilly, J. M., and P. B. Rhines, 2002: Coherent eddies in the Labrador Sea observed from a mooring. J. Phys. Oceanogr., 32, 585-598.

, - - F. Schott, K. Lavender, J. R. N. Lazier, U. Send, and E. D'Asaro, 2003: Observations of the Labrador Sea eddy field. Prog. Oceanogr., 59, 75-176.

Pickart, R. S., D. J. Torres, and R. A. Clarke, 2002: Hydrography of the Labrador Sea during active convection. J. Phys. Oceanogr., 32, 428-457.

Regier, L., and H. Stommel, 1979: Float trajectories in simple kinematic floats. Proc. Natl. Acad. Sci. USA, 76, 17601764.

Spall, M. A., 2004: Boundary currents and water mass transformation in marginal seas. J. Phys. Oceanogr., 34, 11971213.

Straneo, F., 2006a: Heat and freshwater transport through the central Labrador Sea. J. Phys. Oceanogr., 36, 606-628.

- , 2006b: On the connection between dense water formation, overturning, and poleward heat transport in a convective basin. J. Phys. Oceanogr., 36, 1822-1840.

Swift, D., 2007: User manual: Iridium APEX, Amy Bower's Dandelion Experiment (firmware revision: Apf9iSbe41cpDandelion062906). School of Oceanography, University of Washington, $43 \mathrm{pp}$. 